\title{
Design and Simulation of a New Sliding Mode Controller for STATCOM Based Wind Farm
}

\author{
Xiaojuan Sun and Xiaohua Feng \\ School of Electronic Information Engineering, \\ $X i$ ' an Technological University, Xi' an, 710021, China \\ sxj_a@163.com
}

\begin{abstract}
Sliding mode controller (SMC) is a highly significant nonlinear controller under condition of certain and partly uncertain dynamic parameters of system. This paper focused on design and implementation of a sliding mode controller for STATCOM. Intend for its application to wind farm connection to the grid. The proposed inverse system sliding mode controller based on nonlinear feedback linearization technology for system decoupling, which enhance the transient stability of wind farms and stabilizes the grid voltage about the given operating point when the fault occurs closer to the wind farms. The simulation results have shown the improved performance of the proposed controller has better control effectiveness and efficiency compared with the conventional controller of inverse system, the proposed controller on wind power system and which assist in improving capability of the wind farms to ride through disturbances, dynamic power flow control of the transmission lines, enhancing power oscillation damping under a sudden fault. Moreover, the proposed control scheme is very simple and easy to implement.
\end{abstract}

Keywords: sliding mode controller, STATCOM, wind farm, inverse system, transient stability, PI control

\section{Introduction}

Due to the technology innovation and cost reduction, during the last two decades, renewable wind energy is enjoying a rapid growth globally to become an important green electricity source to replace polluting and exhausting fossil fuel. Wind energy has been noted as the fastest growing renewable power generation technology in the world, with an annual growth rate in excess of $30 \%$ and a foreseeable penetration of $12 \%$ of global electricity demand by 2020[1-3]. The installed capacity of wind power increased constantly year by year, the integration of lots of wind power and grid changed original load flow of the power system. However, wind energy is random and wind farm is composed of large number of induction generators which are different from synchronous machine. So the power quality of the wind farms has become a significant issue for both power system and customers. Under these conditions, the modern power systems are facing some major challenges such as voltage regulation, power flow control, transient stability, and of power oscillation, etc $[4,5]$.

In a power distribution system, voltage sag contributes more than $80 \%$ of power quality (PQ) problems that exist in power systems. It is caused by a fault in the utility system, a fault within the customer's facility or a large increase of the load current, like starting a motor or transformer energizing, operation of process controllers. The 
STATCOM (static synchronous compensator) is considered for this application, because it provides many advantages, in particular the fast response time and superior voltage support capability with its nature of voltage source. Controlled reactive power sources are commonly used for load voltage regulation in presence of disturbances like voltage sag. Due to their high control bandwidth, STATCOM based on three-phase pulse width modulation voltage source converters, have been proposed for this application [6]. With the recent innovations in high power semiconductor switch, converter topology and digital control technology [7-9], which is promising to help integrate wind energy into the grid to achieve a more cost-effective and reliable renewable wind energy. STATCOM consist of an inverter, transformers, a parallel converter, capacitor, and control block $[10,11]$. The typical application of STATCOM is to support reactive power by leading electronics switches trigging to control a single output voltage basic wave form. Both output voltage angle and amplitude are two control parameters of STATCOM and they can provide voltage support and the reactive power. Consequently, the reactive power control system depends on the capacitor voltage dynamics, which has to be kept relatively slow. If someone wants to achieve the faster dynamics current controller, you must design a fast control strategy implementation.

In order to ensure the fast response time and superior voltage support capability, this paper presents a sliding mode controller for STATCOM based wind farm. The remainder of this paper is organized as follows. In section 2, the dynamic model of power system and controller design is depicted. In Section 3, the dynamic simulations works are carried out for the wind power to verify the performance of the proposed STATCOM and its strategy. Finally, conclusions are drawn in Section 4.

\section{System Model and Controller Design}

\subsection{System Model}

Figure 1 shows the system under study. The power system is represented by grid.

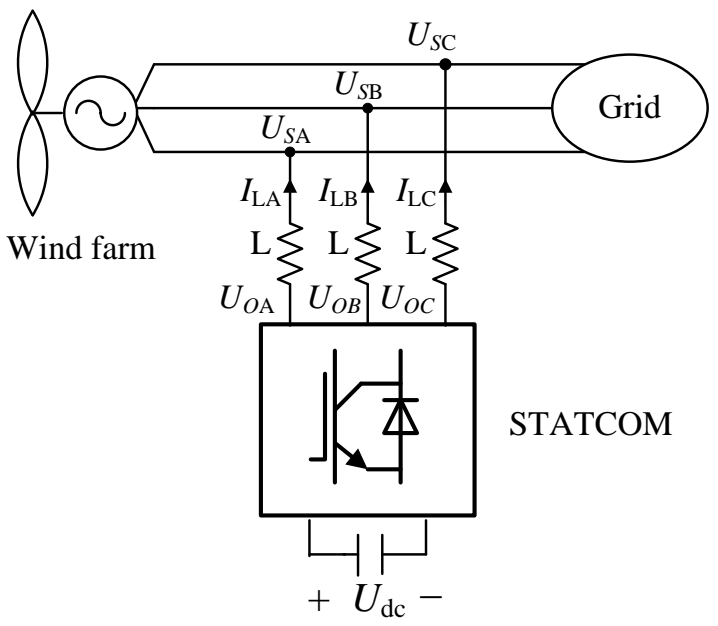

Figure 1. Schematic Configuration of the System with STATCOM

The system considered here is a simplified model of a wind farm with STATCOM. To facilitate the analysis, Figure1 ignores the resistance of the inverter part and $\mathrm{L}$ is inductance 
of inverter side. $U_{S A}, U_{S B}$ and $U_{S C}$ are three phase voltage of system grid; $U_{O A}, U_{O B}$ and $U_{O C}$ are three phase output voltage of the STATCOM; $I_{L A}, I_{L B}$ and $I_{L C}$ are three phase output current of the STATCOM; $U_{d c}$ is the voltage of the DC voltage in inverter side. The STATCOM is represented by as the third order nonlinear model [12].

$$
\left\{\begin{array}{l}
\frac{d I_{L d}}{d t}=-\frac{U_{O d}}{L}+\frac{U_{S d}}{L}+\omega I_{L q} \\
\frac{d I_{L q}}{d t}=-\frac{U_{O q}}{L}+\frac{U_{S q}}{L}-\omega I_{L d} \\
C \frac{d U_{d c}}{d t}=\frac{3}{2} \frac{U_{O d} I_{L d}+U_{O q} I_{L q}}{U_{d c}}
\end{array}\right.
$$

Here $\omega$ is the angular frequency of system, $I_{L d}$ is the $\mathrm{d}$ axis $\mathrm{AC}$ current component in inverter side, $I_{L q}$ is the q axis $\mathrm{AC}$ current component in inverter side, $U_{O d}$ is the $\mathrm{d}$ axis $\mathrm{AC}$ voltage component in inverter side, $U_{O q}$ is the q axis $\mathrm{AC}$ voltage component in inverter side, $U_{S d}$ and $U_{S q}$ are the $\mathrm{d}$ axis and q axis voltage component of three phase voltage of system grid respectively.

Equation (1) is a third order nonlinear coupled mathematical model of STATCOM. That is a traditional multi-variable, nonlinear and coupled system, and control accuracy, dynamic performance of such system can not be met by classic control. It was more dependent on motor parameters, once the parameters had changed, the effect of the system control would be affected. So the coupling and the design process would be complex. It applied the inverse system method based on nonlinear feedback linearization technology for system decoupling in this paper [13-15].

\subsection{Controller Design}

Assuming that the dynamics of the DC bus voltage is much slower than that of the AC currents, the value $U_{d c}$ in each sample period can be considered constant. Then the states of the STATCOM are:

$$
X=\left[x_{1}, x_{2}\right]^{\mathrm{T}}=\left[I_{L d}, I_{L q}\right]^{\mathrm{T}}
$$

Take the input variables :

$$
U=\left[u_{1}, u_{2}\right]^{\mathrm{T}}=\left[U_{O d}, U_{O q}\right]^{\mathrm{T}}
$$

Take the output variables:

$$
Y=\left[y_{1}, y_{2}\right]^{\mathrm{T}}=\left[I_{L d}, I_{L q}^{\mathrm{T}}\right]
$$

So the invert system expression of STATCOM mathematical model can be got as equation (5).

$$
\dot{X}=f(X, U)=\left\{\begin{array}{l}
\frac{U_{S d}}{L}-\frac{u_{1}}{L}+\omega x_{2} \\
\frac{U_{S q}}{L}-\frac{u_{2}}{L}-\omega x_{1}
\end{array}\right.
$$


Thus it can be seen that STATCOM is a nonlinear system which has two inputs and two outputs. Let's define the virtual inputs as:

$$
\left\{\begin{array}{l}
v_{1}=\dot{y}_{1} \\
v_{2}=\dot{y}_{2}
\end{array}\right.
$$

Take $\mathrm{z}_{1}=\mathrm{y}_{1}, \mathrm{z}_{2}=\mathrm{y}_{2}$, then the standard form of STATCOM are:

$$
\left\{\begin{array}{c}
\dot{z}_{1}=v_{1} \\
\dot{z}_{2}=v_{2} \\
U=\Phi(z, v)
\end{array}\right.
$$

Where $z=\left[\mathrm{z}_{1}, \mathrm{z}_{2}\right]^{\mathrm{T}} ; v=\left[\mathrm{v}_{1}, \mathrm{v}_{2}\right]^{\mathrm{T}}$.

As a kind of robust nonlinear feedback control method, sliding mode control is able to respond quickly, invariant to systemic parameters and external disturbance. Determining a sliding surface is the key of sliding mode control. The design of sliding mode controller can be used to stabilize the state of the system near the sliding surface as the result in the stability of control system only when the changed sliding surface meet $s \dot{s}<0$. In order to reduce the intensity of buffeting on the symbolic function smoothing, this paper adopts exponential reaching law mode

$$
\dot{S}=\varepsilon \operatorname{sgn}(S)-k S
$$

Define the following sliding mode switching function: $S=\left[S_{1} S_{2}\right]^{T}$, design of the controller for equation (7) and take sliding surface respectively as:

$$
\left\{\begin{array}{l}
S_{1}=z_{1}-z_{1}^{*} \\
S_{2}=z_{2}-z_{2}^{*}
\end{array}\right.
$$

Where $z_{1}^{*}=I_{L d}^{*}, z_{2}^{*}=I_{L q}^{*}$.

Combined with the sliding mode reaching law of equation (9), then

$$
\left\{\begin{array}{c}
\dot{S}_{1}=-\varepsilon_{1} \operatorname{sgn}\left(S_{1}\right)-k_{1} S_{1} \\
\dot{S}_{2}=-\varepsilon_{2} \operatorname{sgn}\left(S_{2}\right)-k_{2} S_{2}
\end{array}\right.
$$

Thus, virtual control V can be obtained as:

$$
\left\{\begin{array}{c}
v_{1}=-\varepsilon_{1} \operatorname{sgn}\left(S_{1}\right)-k_{1} S_{1} \\
v_{2}=-\varepsilon_{2} \operatorname{sgn}\left(S_{2}\right)-k_{2} S_{2}
\end{array}\right.
$$


To eliminating the references changes varying with system parameters, PI regulator can be used. Finally, perform inverse we can get the control input $U$. Then the two order control system is designed sliding mode control strategy above as its final control result.

\section{Simulation Results and Discussion}

In order to validate the mathematical analysis and, hence, to establish the effectiveness of the proposed control scheme, simulations works are carried out for the wind power as Figure1. Performance of the proposed model and the controller design were verified using computer simulation performed in SIMULINK/MATLAB. In addition, the simulation results of the proposed model and the PSB in SIMULINK/MATLAB are compared in order to verify the proposed model. The wind farm consisting of six $1.5 \mathrm{MW}$ wind turbines is connected to a $25 \mathrm{kV}$ distribution system exports power to a $120 \mathrm{kV}$ grid through a $25 \mathrm{kV}$ feeder. The $9 \mathrm{MW}$ wind farm is simulated by three pairs of $1.5 \mathrm{MW}$ wind turbines. Wind turbines use squirrel-cage induction generators. The stator winding is connected directly to the $50 \mathrm{~Hz}$ grid and the rotor is driven by a variable-pitch wind turbine. Reactive power absorbed by the induction generators is partly compensated by capacitor banks connected at each wind turbine low voltage bus. The rest of reactive power required to maintain the $25 \mathrm{kV}$ voltage at bus close to $1 \mathrm{pu}$. is provided by the STATCOM. The wind speed applied to each turbine is $9 \mathrm{~m} / \mathrm{s}$.

The simulation parameters: Each wind turbine mechanical output power is $1.5 \mathrm{MW}$, inductances of three phase PI section line are $3.5 \mathrm{H} / \mathrm{m}$, and maximum pitch angle is $45 \mathrm{deg}$. At nominal power, each pair of wind turbine absorbs $2 \mathrm{M}$ Var. The fault occurs closer to the B25 bus bar at $t=2 s$ and remove by opening the barkers of the faulted line at $t=2.1 \mathrm{~s}$. Stator resistance is 0.435 , leakage inductance of the rotor is $2 \mathrm{mH}$, rotor resistance is 0.81 , leakage inductance of the rotor is $69.31 \mathrm{mH}$, Inertia of rotation is $0.089 \mathrm{~kg} / \mathrm{m}$. Line resistance is 0.05 $\Omega$, DC bus capacitor is $\mathrm{C}=2200 \mathrm{uf}$.To verify the flexibility and stability of the proposed control scheme, the simulation showed the results compare with control of inverse system [16]. Start simulation and observe the signals on the wind turbines scope monitoring terminal voltage, active and reactive power.

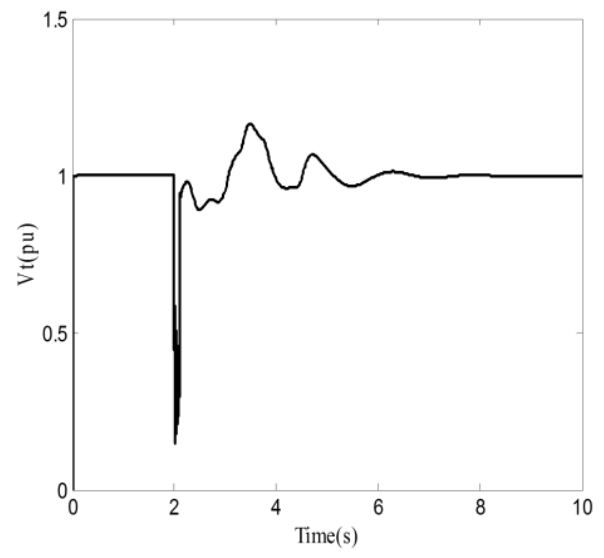

(a) Grid Voltage by Classical PI Control of Inverse System 


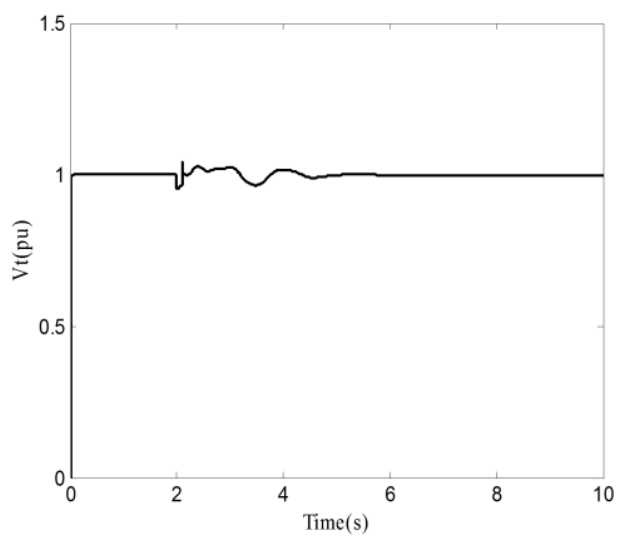

(b) Grid Voltage by Sliding Mode Control

Figure 2. Grid Voltage Simulation Results with Classical PI Control and Sliding Mode Control of Inverse System

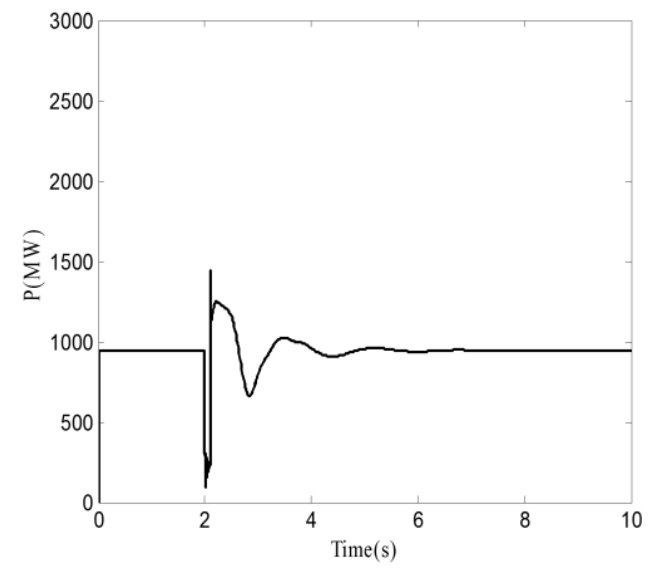

(a) Active power (P) by Classical PI Control of Inverse System

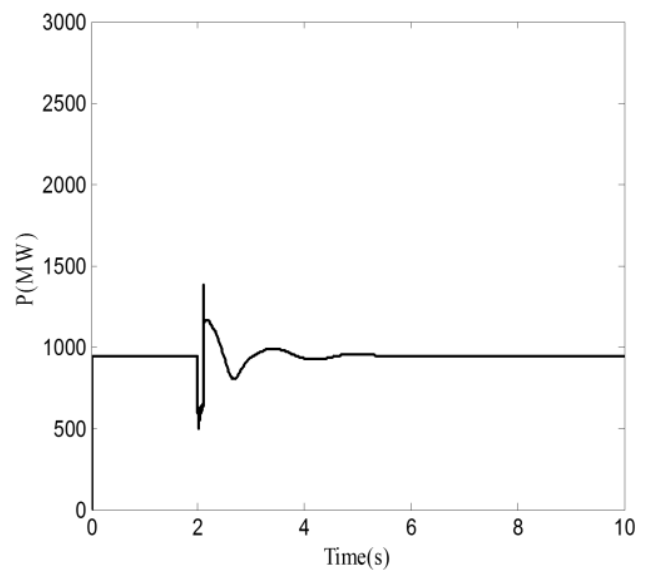

(b) Active Power (P) by Sliding Mode Control

Figure 3. Active Power Simulation Results with Classical PI Control and Sliding Mode Control of Inverse System 


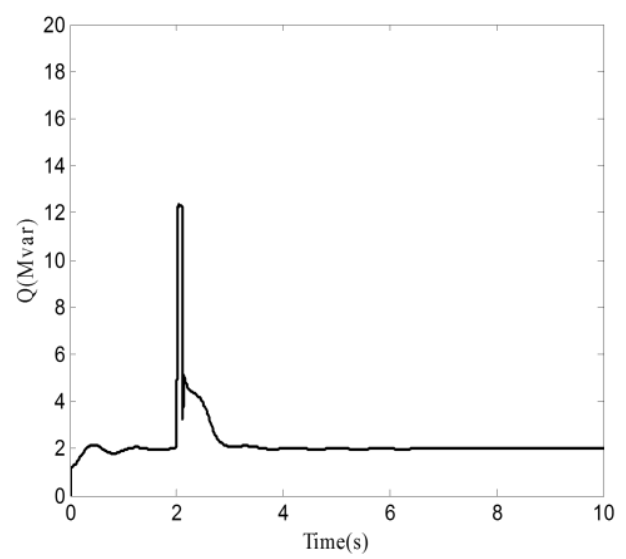

(a) Reactive power (Q) by classical PI control of inverse system

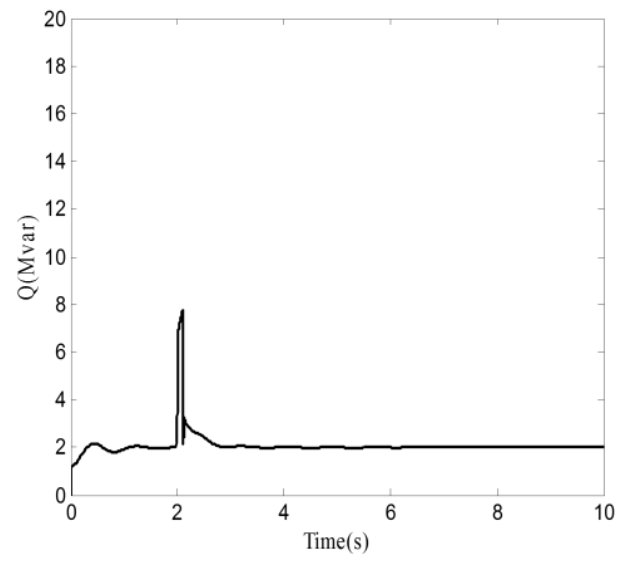

(b) Reactive power $(\mathrm{Q})$ by sliding mode control

\section{Figure 4. Reactive Power Simulation Results with Classical PI Control and Sliding Mode Control of Inverse System}

The Figure 2 show the grid voltage $\left(\mathrm{V}_{\mathrm{t}}\right)$ simulation results with classical PI control inverse system and Sliding Mode Control of inverse system, the Figure 3 show the active power $(\mathrm{P})$ simulation results and the figure 4 show the reactive power $(\mathrm{Q})$ simulation results.

When grid A phase voltage drop 20\% in 2 seconds, and recover in 2.1seconds. As shown in Figure 2, the grid voltage is dropped $0.3 \mathrm{pu}$., we can see that the grid voltage with sliding mode controller reaches its reference within $1 \mathrm{~s}$, but the grid voltage with PI controller reaches its reference take longer time to recover. Additionally, the responses of the sliding mode control can provide good damping to the oscillatory of the system. It can be seen from Figure 3 and Figure 4, active power and reactive power also have a good rising and settling time with sliding mode controller than the classical PI controller. When A phase of grid voltage drop $20 \%$, using the sliding mode control strategy, the grid voltage is relatively stable, active power and reactive power fluctuation is small.

Above of all, as can be seen the post fault are come into a new equilibrium, sliding mode controller provides good damping to the oscillatory of the system, grid voltage is regulated to its first failure value very quickly, active power and reactive power can also be stabilized 
soon in the new value. It is quite evident that the proposed controller achieves good transient stability and voltage regulation than classical PI control of inverse system. The simulation results show that the control method in this paper has good dynamic stability.

\section{Conclusion}

High penetration of wind power in the power system has caused new challenges to the operation, control and stability of modern electric power system. This work reveals that there has been a significant increase in interest of STATCOM and its control methods. A sliding mode controller has been designed in this paper for external control of a STATCOM connected to the wind farm.

Performance of the propose model and the controller design are verified by using computer simulation performed in SIMULINK/MATLAB. The simulation results show that the STATCOM with proposed sliding mode controller can assist in improving capability of the wind farms to ride through disturbances, it's reaching time and tracking error in the approaching phase can be significantly reduced, dynamic power flow control of the transmission on lines, enhancing power oscillation damping. Comparing with the classical PI controller of inverse system, the proposed sliding mode controller is more effective and more stable for damping the speed deviations of the system grid under a sudden fault.

\section{References}

[1] R. Chedid, "Intelligent Control for Wind Energy Conversion Systems", Wind Engineering, vol. 22, no. $1,(\mathbf{1 9 9 8})$, pp. 1-16.

[2] T. Ackermann and L. Soder, "An Overview of Wind Energy-status 2002", Renewable and Sustainable Energy Reviews”, vol. 6, no. 1-2, (2002), pp. 67-127.

[3] D. Barry, "Increasing Renewable Energy Accessibility in Ireland", Proc. 19 ${ }^{\text {th }}$ world Energy Congr., (2004), pp. 1-10.

[4] M. Gordon and D.J. Hill, "Flexible Nonlinear Voltage Control Design for Power System," Proc. IEEE Int. Conf. on Control Appl., (2007); Singapore

[5] Y. Guo, D.J. Hill, and Y. Wang, "Nonlinear Decentralized Control of Large-scale Power Systems", Automatica, vol. 36, no. 9, (2000), pp.1275-1289.

[6] K. Somsai, N. Voraphonpiput and T. Kulworawanichpong, "Loop Shaping Control of Distribution STATCOM", International Journal of Control and Automation, vol. 6, no. 1, (2013), pp. 87-104.

[7] C. Han, Z. Yang and A. Edris, "System Integration and Demonstration of a 4.5MVA STATCOM based on Emitter turn -off (ETO) Thyristor and Cascade Multilevel Converter", Proc. IEEE-IECON, (2005).

[8] S. Sirisukprasert, A. Q. Huang and J. S. Lai, "Modeling, Analysis and Control of Cascaded-Multilevel Convert-based STATCOM", IEEE PES General Meeting, (2003).

[9] Y. Guo, D. J. Hill and Y. Wang, "Global Transient Stability and Voltage Regulation for Power Systems", IEEE Trans on. Power Systems, (2001), vol. 16, no. 4, pp. 678-688.

[10] G. Chicco, M. Molinas and T.Undeland, "Improvement of the Transient Stability Margin in Wind Systems with a STATCOM", Proc. VI World Energy Syst. Conf., (2006).

[11] M. Molins, J. Kondoh and J. A Suul, "Reactive Support for Wind and Wave Farms with a STATCOM for Integration into the Power System”, Proc. Renewable Energy Conf., (2006).

[12] C. Zou, B. Wang and P. Bao, "Application of STATCOM in Wind Farm”, Electric Drive, vol. 38, no. 12, (2008), pp. 46-49.

[13] J. Zhang, G. Liu and J. Li, “ Improved Control of Wind Power Generation Based on Variable Structure Slide Mode and Inverse System”, International Journal of Control and Automation, vol. 6, no. 5,(2013), pp.277294.

[14] A. Mullane, G. Lightbody and R. Yacamini, "Comparison of a Casade and Feedback Linearization Scheme for DC Link Voltage Control in a Grid Connected Wind Turbine”, Proceeding of the 36thUniversities Power Engineering Conference, IEEE, (2001); September: UK.

[15] T. Li, Z. Tong and B. Wang, "Direct Power Control of Three Phase PWM Rectifier Based on the Inverse System Theory”, Journal of Electric Drive, vol. 38, no.10,(2008), pp.33-38. 
[16] Y. Wei , R. D. LI, "Design of Nonlinear Optimal Excitation Controller with Voltage Feedback", Power System Protection and Control, vol. 38, no.14, (2010), pp.110-114.

\section{Authors}

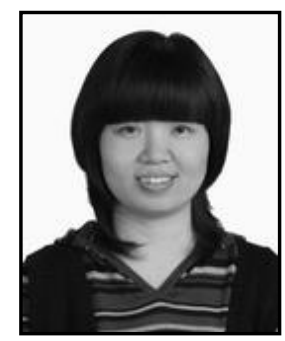

Xiaojuan Sun received the B.E. degree from the North Western Polytechnical University, Xi'an, Shaanxi, China, in 1998. In 2004, She received the M.E. degree from the Xi'an University of Technology, Xi'an, Shanxi, China, and she is a Ph.D. student of Power Electrical Engineering, Xi'an University of Technology, Currently, she is an Associate Professor at the School of Control and Computer Engineering, Xi'an Technological University, Xi'an, Shaanxi, China. Her research interests include theories and applications of power system control design, under-actuated system control, sliding-mode control, process control, etc.

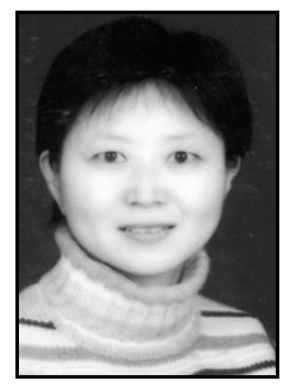

Xiaohua Feng received the B.E. degree from the Taiyuan University of Technology, Taiyuan, Shanxi, China, in 1998. In 2004, She received the M.E. degree from the Xi'an University of Technology, Xi'an, Shaanxi, China, and she is a Ph.D. student of Power Electrical Engineering, North Western Polytechnical University, Currently, she is an Associate Professor at the School of Control and Computer Engineering, Xi' an Technological University, Xi'an, Shaanxi, China. Her research interests include linear system theory, stochastic estimation and control, continuous time Markov decision processes, optimization and operations research. etc. 
International Journal of Control and Automation Vol.7, No.7 (2014) 